\title{
Impact of Physician Volume and Specialty on In-Hospital Mortality of Ischemic and Hemorrhagic Stroke
}

\author{
Kunihiro Nishimura, MD, PhD; Kuniaki Ogasawara, MD, PhD; Takanari Kitazono, MD, PhD; \\ Koji Iihara, MD, $\mathrm{PhD}$ on behalf of the J-ASPECT Study Collaborators
}

\begin{abstract}
Background: The degree of association between mortality and case volume/physician volume is well known for many surgical procedures and medical conditions. However, the link between physician volume and death rate in patients hospitalized for stroke remains unclear. This study analyzed the correlation between in-hospital stroke mortality and physician volume per hospital, considering board certification status.
\end{abstract}

\begin{abstract}
Methods and Results: For this retrospective registry-based cohort study, data were obtained from the Japanese nationwide registry on patients hospitalized for ischemic stroke, intracerebral hemorrhage $(\mathrm{ICH})$, and subarachnoid hemorrhage (SAH) between 2010 and 2016. The number of stroke care physicians and relevant board-certified physicians was also obtained. Odd ratios (ORs) of 30-day in-hospital mortality were estimated after adjusting for institutional and patient differences using generalized mixed logistic regression. From 295,150 (ischemic stroke), 98,657 (ICH), and 36,174 (SAH) patients, 30-day in-hospital mortality rates were 4.4\%, $16.0 \%$, and $26.6 \%$, respectively. There was a correlation between case volume and physician volume. A higher number of stroke care physicians was associated with a reduction in 30-day mortality after adjusting for stroke case volume and comorbidities for all stroke types (all P for trend<0.05).
\end{abstract}

Conclusions: An increased number of stroke care physicians was associated with reduced in-hospital mortality for all types of stroke. The volume threshold of board-certified physicians depends on the specialty and stroke type.

Key Words: Endovascular surgery; Outcome; Stroke

$\mathbf{S}$ troke is an important cause of disability and death worldwide. In Japan, stroke is the fourth-leading cause of death, as well as a leading cause of longterm disability. Almost 270,000 individuals in Japan have a new or recurrent stroke each year, and nearly 120,000 individuals die following a stroke. ${ }^{1}$ Similar to other Asian countries, hemorrhagic stroke is still prevalent in Japan.

Board-certified physicians responsible for stroke care, such as neurosurgeons, neurologists, stroke physicians, and endovascular surgeons, are required to complete intensive training programs and to pass examinations. The certification is effective for a limited time, and stroke physicians need to keep up with the latest clinical advances and successfully complete recertification. The degree of association between mortality and case volume and physician volume is well known for many surgical procedures and medical conditions. $^{1-3}$ Three studies on the association between case volume and stroke outcome are also available, but the association between mortality and case volume is controversial. ${ }^{46}$

There is little information as to whether the institutional number of stroke care physicians with or without relevant board certification is related to better prognosis for stroke patients in clinical practice, except for ischemic stroke. ${ }^{6}$ In addition, the number of specialized board-certified physicians needed for comprehensive stroke centers has not been clearly determined.

The aim of this study was to determine whether the institutional number of stroke care physicians and their specialties are related to the prognosis of stroke patients using a large, nationwide, dataset, the J-ASPECT Study.

\section{Methods}

Assessment of Physician Volume by Institutional Survey Participation in the J-ASPECT Study was voluntary in collaboration with the Japan Neurosurgical Society and Japan Stroke Society. Physician volume related to stroke

Received December 2, 2020; revised manuscript received June 15, 2021; accepted July 8, 2021; J-STAGE Advance Publication released online August 13, 2021 Time for primary review: 41 days

Department of Preventive Medicine and Epidemiology, National Cerebral and Cardiovascular Center, Suita (K.N.); Department of Neurosurgery, Iwate Medical University, Morioka (K.O.); Department of Medicine and Clinical Science, Kyushu University Graduate School of Medical Sciences, Fukuoka (T.K.); and National Cerebral and Cardiovascular Center, Suita (K.I.), Japan

Mailing address: Kunihiro Nishimura, MD, PhD, Director, Department of Preventive Medicine and Epidemiology, National Cerebral and Cardiovascular Center, 6-1 Kishibeshin-machi, Suita 564-8565, Japan. E-mail: knishimu@ncvc.go.jp

All rights are reserved to the Japanese Circulation Society. For permissions, please e-mail: cj@j-circ.or.jp

ISSN-1346-9843 


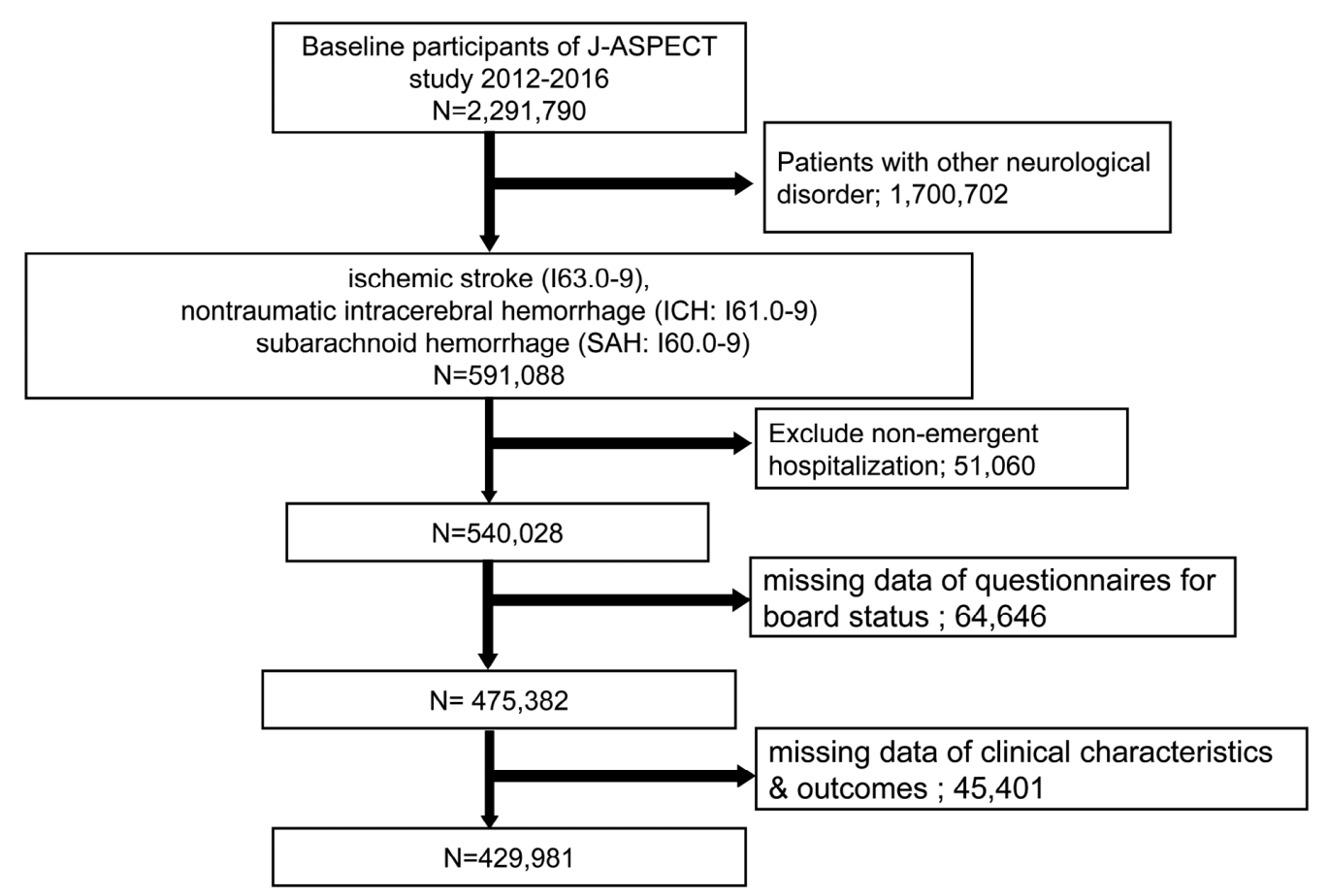

Figure 1. Enrolment and completeness of data. $\mathrm{ICH}$, intracerebral hemorrhage; $\mathrm{SAH}$, subarachnoid hemorrhage.

care was assessed based on the results of an institutional J-ASPECT surveys regarding comprehensive stroke care capabilities in 2010 and 2014..$^{1,7,8}$ The details of these institutional surveys have been reported previously. ${ }^{1,7}$ In this study we assessed physician volume related to stroke care, per institute, in 2 ways: (1) full-time physicians working in stroke care regardless of board certification status (stroke care physician); and (2) board-certified physicians in any of the 4 relevant societies.

\section{Clinical Data Sources and Sample Strategy}

The J-ASPECT Study Group analyzed the Diagnosis Procedure Combination database to gain new clinical insights, ${ }^{7-9}$ and we used this approach again in the present study. We identified patients hospitalized for stroke in a deidentified discharge database using the same method as for previous J-ASPECT studies; ${ }^{7,10,11}$ details are provided in the Supplementary Material. In all, 429,981 consecutive patients with stroke were included in this study after patients had been excluded due to missing data, other diseases, or by opting out of the study (Figure 1). The response rate of the surveys was $54.7 \%(749 / 1,369)$ in 2010 and $33.6 \%$ $(532 / 1,585)$ in 2014.

\section{Outcomes}

The primary outcome was the occurrence of 30-day inhospital mortality from any cause, not necessarily stroke related. To examine the association between physician volume and outcome, the number of physicians in each institute in the 2010 and $2014 \mathrm{~J}$-ASPECT institutional survey was used to analyze the outcomes of acute stroke patients hospitalized between April 1, 2010 and March 31, 2014, as well as between April 1, 2014 and March 31, 2016, respectively.

\section{Statistical Analysis}

We examined the association between stroke care physician volume and the in-hospital mortality risk of patients hospitalized for stroke. Mixed-effect logistic regression models with random intercept were used to consider hospital variation in the J-ASPECT database. Physician volume was included in the models, which also included age, Charlson scores, presence of coma, comorbidity (hypertension, diabetes, and hyperlipidemia), and the stroke case volume per institute as fixed effects.

The random intercept for each institution allowed us to include unmeasured processes for the outcome specific to each institute. Considering that the association between the physician volume in each institute and the 30-day inhospital mortality was not linear, we used a systematic search for the best-fitting linear spline function or fractional polynomial function for physician volume using the MVRS command in Stata ${ }^{\mathbf{2 2 , 1 3}}$ (for other details, refer to the Supplementary Material). All analyses were performed using STATA version 15 (StataCorp, College Station, TX, USA).

\section{Results}

The results of the survey of board-certified physician volume per hospital are summarized in Table 1. In 2010 and 2014, 749 and 532 hospitals, respectively, responded to the institutional survey. Of these, 264 and 297 hospitals, respectively, registered their clinical information. Background characteristics based on the number of stroke care physicians are summarized in Table 1. The mean age of patients seemed to be lower in institutes with a higher physician volume $(\mathrm{P}<0.001)$ and there was a slight gender difference of patients exist. The 30-day mortality rate and the rate of 


\begin{tabular}{|c|c|c|c|c|c|c|c|}
\hline & \multicolumn{5}{|c|}{ Ischemic stroke } & \multirow{2}{*}{\multicolumn{2}{|c|}{$\begin{array}{c}\text { Intracerebral hemorrhage } \\
\text { No. physicians }\end{array}$}} \\
\hline & \multicolumn{4}{|c|}{ No. physicians } & \multirow[t]{2}{*}{$P$ value } & & \\
\hline & $1-3$ & $4-6$ & $7-9$ & $\geq 10$ & & $1-3$ & $4-6$ \\
\hline No. cases & 81,907 & 85,095 & 62,112 & 56,766 & & 25,998 & 29,213 \\
\hline Age (years) & $75.2 \pm 12.3$ & $74.3 \pm 12.5$ & $73.6 \pm 126$ & $73.1 \pm 12.8$ & $<0.001$ & $70.76 \pm 13.9$ & $70.15 \pm 13.8$ \\
\hline Male sex & $\begin{array}{c}46,159 \\
(56.4)\end{array}$ & $\begin{array}{c}50,039 \\
(58.8)\end{array}$ & $\begin{array}{c}36,906 \\
(59.4)\end{array}$ & $\begin{array}{c}34,069 \\
(60.0)\end{array}$ & $<0.001$ & $\begin{array}{l}14,358 \\
(55.2)\end{array}$ & $\begin{array}{l}16,415 \\
(56.2)\end{array}$ \\
\hline \multicolumn{8}{|l|}{ Japan Coma Scale } \\
\hline 0 digit & $\begin{array}{l}39,513 \\
(48.2)\end{array}$ & $\begin{array}{c}40,386 \\
(47.5)\end{array}$ & $\begin{array}{c}30,377 \\
(48.9)\end{array}$ & $\begin{array}{c}28,104 \\
(49.5)\end{array}$ & $<0.001$ & $\begin{array}{l}5,632 \\
(21.7)\end{array}$ & $\begin{array}{l}5,791 \\
(19.8)\end{array}$ \\
\hline 1 digit & $\begin{array}{l}30,515 \\
(37.3)\end{array}$ & $\begin{array}{c}33,471 \\
(39.3)\end{array}$ & $\begin{array}{l}23,839 \\
(38.4)\end{array}$ & $\begin{array}{l}21,706 \\
(38.2)\end{array}$ & & $\begin{array}{l}9,778 \\
(37.6)\end{array}$ & $\begin{array}{l}11,461 \\
(39.2)\end{array}$ \\
\hline 2 digit & $\begin{array}{l}7,573 \\
(9.2)\end{array}$ & $\begin{array}{c}7,226 \\
(8.5)\end{array}$ & $\begin{array}{c}5,095 \\
(8.2)\end{array}$ & $\begin{array}{c}4,639 \\
(8.2)\end{array}$ & & $\begin{array}{l}4,552 \\
(17.5)\end{array}$ & $\begin{array}{l}5,409 \\
(18.5)\end{array}$ \\
\hline 3 digit (coma) & $\begin{array}{l}4,306 \\
(5.3)\end{array}$ & $\begin{array}{l}4,012 \\
(4.7)\end{array}$ & $\begin{array}{c}2,801 \\
(4.5)\end{array}$ & $\begin{array}{c}2,317 \\
(4.1)\end{array}$ & & $\begin{array}{l}6,036 \\
(23.2)\end{array}$ & $\begin{array}{l}6,552 \\
(22.4)\end{array}$ \\
\hline 30-day mortality & $\begin{array}{c}4,340 \\
(5.3)\end{array}$ & $\begin{array}{l}3,876 \\
(4.6)\end{array}$ & $\begin{array}{c}2,588 \\
(4.2)\end{array}$ & $\begin{array}{c}2,046 \\
(3.6)\end{array}$ & $<0.001$ & $\begin{array}{l}4,470 \\
(17.2)\end{array}$ & $\begin{array}{l}4,680 \\
(16.0)\end{array}$ \\
\hline mRS 0-2 & $\begin{array}{l}41,499 \\
(52.7)\end{array}$ & $\begin{array}{l}44,611 \\
(53.8)\end{array}$ & $\begin{array}{l}34,243 \\
(56.8)\end{array}$ & $\begin{array}{c}31,850 \\
(57.5)\end{array}$ & $<0.001$ & $\begin{array}{l}7,367 \\
(29.0)\end{array}$ & $\begin{array}{l}8,475 \\
(29.5)\end{array}$ \\
\hline LOS (days) & $\begin{array}{c}19 \\
{[11-34]}\end{array}$ & $\begin{array}{c}18 \\
{[10-32]}\end{array}$ & $\begin{array}{c}17 \\
{[10-30]}\end{array}$ & $\begin{array}{c}17 \\
{[10-29]}\end{array}$ & $<0.001$ & $\begin{array}{c}24 \\
{[12-42]}\end{array}$ & $\begin{array}{c}23 \\
{[11-39]}\end{array}$ \\
\hline Case volume/year & $\begin{array}{c}183 \\
{[130-254]}\end{array}$ & $\begin{array}{c}271 \\
{[196-342]}\end{array}$ & $\begin{array}{c}321 \\
{[226-472]}\end{array}$ & $\begin{array}{c}397 \\
{[264-577]}\end{array}$ & $<0.001$ & $\begin{array}{c}62 \\
{[41-86]}\end{array}$ & $\begin{array}{c}88 \\
{[64-120]}\end{array}$ \\
\hline Hypertension & $\begin{array}{c}57,673 \\
(70.4)\end{array}$ & $\begin{array}{c}62,594 \\
(73.6)\end{array}$ & $\begin{array}{l}45,138 \\
(72.7)\end{array}$ & $\begin{array}{c}42,673 \\
(75.2)\end{array}$ & $<0.001$ & $\begin{array}{c}23,732 \\
(91.3)\end{array}$ & $\begin{array}{c}26,972 \\
(92.3)\end{array}$ \\
\hline Diabetes & $\begin{array}{c}23,258 \\
(28.4)\end{array}$ & $\begin{array}{c}24,538 \\
(28.8)\end{array}$ & $\begin{array}{c}18,461 \\
(29.7)\end{array}$ & $\begin{array}{c}16,726 \\
(29.5)\end{array}$ & $<0.001$ & $\begin{array}{l}5,410 \\
(20.8)\end{array}$ & $\begin{array}{l}6,228 \\
(21.3)\end{array}$ \\
\hline Hyperlipidemia & $\begin{array}{c}28,391 \\
(34.7)\end{array}$ & $\begin{array}{c}33,029 \\
(38.8)\end{array}$ & $\begin{array}{c}27,487 \\
(44.3)\end{array}$ & $\begin{array}{c}28,376 \\
(50.0)\end{array}$ & $<0.001$ & $\begin{array}{l}4,841 \\
(18.6)\end{array}$ & $\begin{array}{l}5,683 \\
(19.5)\end{array}$ \\
\hline
\end{tabular}

(Table 1 continued the next page.)

modified Rankin Scale (mRS) 0-2, which suggests severe neurological dysfunction, were lower in institutes with a high physician volume for all stroke subtype (all $\mathrm{P}<0.001$ ).

There was a median of 7 full-time stroke care physicians per hospital in both the 2010 and 2014 surveys (Supplementary Table 1). In Japan, the number of board-certified neurosurgeons for stroke care is greater than that of board-certified neurologists. The Japan Stroke Society also authorized stroke care-specific board-certification for neurologists and neurosurgeons.

Patients' clinical presentations and facilities' characteristics are presented in Table 2. The final study sample included 429,981 patients with stroke $(295,150$ [68.6\%], 98,657 [22.9\%], and 36,174 [8.4\%] patients with ischemic stroke, $\mathrm{ICH}$, and SAH, respectively), who were admitted to the participating hospitals in the J-ASPECT Study.

Although there was a positive correlation between the number of full-time stroke care physicians and the case volume of stroke types, the correlation was weak (Pearson's correlation coefficient was $0.32,0.43,0.32$ for ischemic stroke, ICH and SAH, respectively; Figure 2).

For all types of stroke, unadjusted analysis revealed a linear trend for lower in-hospital mortality with an increase in the number of full-time stroke care physicians, regardless of their board certification status (Supplementary Figure; all $\mathrm{P}$ for trend $<0.001$ ).

The institutional number of physicians was related to lower in-hospital mortality. The best-fitting model for the association was a linear spline model. An association between lower in-hospital mortality and higher quartile of full-time stroke care physicians was observed after multivariable adjustment for case volume and comorbidities (Figure 3; P for trend $=0.012,<0.001,0.032$ for ischemic stroke, intracerebral hemorrhage, and subarachnoid hemorrhage, respectively). The odds ratios (ORs) for 30-day in-hospital mortality for ischemic stroke, $\mathrm{ICH}$, and SAH in hospitals with the highest volume of full-time stroke care physicians were 0.89 (95\% confidence interval [CI] 0.79-0.99), 0.78 (95\% CI 0.67-0.91), and $0.81(95 \%$ CI 0.68-0.98), respectively. Interestingly, the age of the physician was not associated with mortality, except for ischemic stroke and in the case of physicians $>60$ years old (Supplementary Table 2).

The number of full-time stroke care physicians was also associated with: specific expertise capabilities; carotid endarterectomy, clipping of intracranial aneurysms, hematoma removal/draining, coiling of intracranial aneurysm and intra-arterial reperfusion therapy, and structure indicators; stroke unit, operating room staff, and interventional services coverage $24 \mathrm{~h}$ a day, 7 days a week (Table 2).

Regarding board certification status, greater numbers of board-certified neurosurgeons and stroke society board physicians per hospital were clear associated with reduced 30-day in-hospital mortality for all types of stroke, but these associations differed according to specialties and stroke types after adjustment for case volume and other comorbidities (Table 3).

We examined changes in the number of board physi- 


\begin{tabular}{|c|c|c|c|c|c|c|c|c|}
\hline & \multicolumn{3}{|c|}{ Intracerebral hemorrhage } & \multicolumn{5}{|c|}{ Subarachnoid hemorrhage } \\
\hline & \multicolumn{2}{|c|}{ No. physicians } & \multirow[t]{2}{*}{$P$ value } & \multicolumn{4}{|c|}{ No. physicians } & \multirow[t]{2}{*}{$P$ value } \\
\hline & $7-9$ & $\geq 10$ & & $1-3$ & $4-6$ & $7-9$ & $\geq 10$ & \\
\hline No. cases & 21,637 & 18,583 & & 8,826 & 10,244 & 8,328 & 8,037 & \\
\hline Age (years) & $69.34 \pm 14.0$ & $68.51 \pm 14.4$ & $<0.001$ & $65.3 \pm 15.5$ & $64.6 \pm 15.4$ & $63.9 \pm 15.4$ & $63.3 \pm 15.7$ & $<0.001$ \\
\hline Male sex & $\begin{array}{c}12,352 \\
(57.1)\end{array}$ & $\begin{array}{c}10,709 \\
(57.6)\end{array}$ & $<0.001$ & $\begin{array}{l}2,832 \\
(32.1)\end{array}$ & $\begin{array}{l}3,309 \\
(32.3)\end{array}$ & $\begin{array}{l}2,836 \\
(34.1)\end{array}$ & $\begin{array}{l}2,672 \\
(33.2)\end{array}$ & 0.021 \\
\hline \multicolumn{9}{|l|}{ Japan Coma Scale } \\
\hline 0 digit & $\begin{array}{l}4,155 \\
(19.2)\end{array}$ & $\begin{array}{l}3,416 \\
(18.4)\end{array}$ & $<0.001$ & $\begin{array}{l}1,824 \\
(20.7)\end{array}$ & $\begin{array}{l}2,113 \\
(20.6)\end{array}$ & $\begin{array}{l}1,739 \\
(20.9)\end{array}$ & $\begin{array}{l}1,691 \\
(21.0)\end{array}$ & 0.530 \\
\hline 1 digit & $\begin{array}{l}8,366 \\
(38.7)\end{array}$ & $\begin{array}{l}7,135 \\
(38.4)\end{array}$ & & $\begin{array}{l}2,058 \\
(23.3)\end{array}$ & $\begin{array}{l}2,419 \\
(23.6)\end{array}$ & $\begin{array}{l}1,995 \\
(24.0)\end{array}$ & $\begin{array}{l}1,962 \\
(24.4)\end{array}$ & \\
\hline 2 digit & $\begin{array}{l}4,003 \\
(18.5)\end{array}$ & $\begin{array}{l}3,562 \\
(19.2)\end{array}$ & & $\begin{array}{l}1,513 \\
(17.1)\end{array}$ & $\begin{array}{l}1,802 \\
(17.6)\end{array}$ & $\begin{array}{l}1,428 \\
(17.1)\end{array}$ & $\begin{array}{l}1,415 \\
(17.6)\end{array}$ & \\
\hline 3 digit (coma) & $\begin{array}{l}5,113 \\
(23.6)\end{array}$ & $\begin{array}{l}4,470 \\
(24.1)\end{array}$ & & $\begin{array}{l}3,431 \\
(38.9)\end{array}$ & $\begin{array}{l}3,910 \\
(38.2)\end{array}$ & $\begin{array}{l}3,166 \\
(38.0)\end{array}$ & $\begin{array}{l}2,969 \\
(36.9)\end{array}$ & \\
\hline 30-day mortality & $\begin{array}{l}3,401 \\
(15.7)\end{array}$ & $\begin{array}{l}2,795 \\
(15.0)\end{array}$ & $<0.001$ & $\begin{array}{l}2,644 \\
(30.0)\end{array}$ & $\begin{array}{l}2,833 \\
(27.7)\end{array}$ & $\begin{array}{l}2,129 \\
(25.6)\end{array}$ & $\begin{array}{l}1,821 \\
(22.7)\end{array}$ & $<0.001$ \\
\hline mRS 0-2 & $\begin{array}{l}6,507 \\
(30.6)\end{array}$ & $\begin{array}{l}5,294 \\
(28.9)\end{array}$ & $<0.001$ & $\begin{array}{l}3,498 \\
(40.8)\end{array}$ & $\begin{array}{l}4,378 \\
(44.1)\end{array}$ & $\begin{array}{l}3,687 \\
(45.5)\end{array}$ & $\begin{array}{l}3,629 \\
(46.3)\end{array}$ & $<0.001$ \\
\hline LOS (days) & $\begin{array}{c}22 \\
{[11-38]}\end{array}$ & $\begin{array}{c}22 \\
{[11-37]}\end{array}$ & $<0.001$ & $\begin{array}{c}25 \\
{[6-46]}\end{array}$ & $\begin{array}{c}26 \\
{[9-46]}\end{array}$ & $\begin{array}{c}26 \\
{[11-45]}\end{array}$ & $\begin{array}{c}28 \\
{[12-46]}\end{array}$ & $<0.001$ \\
\hline Case volume/year & $\begin{array}{c}106 \\
{[73-140]}\end{array}$ & $\begin{array}{c}118 \\
{[79-148]}\end{array}$ & $<0.001$ & $\begin{array}{c}23 \\
{[16-34]}\end{array}$ & $\begin{array}{c}33 \\
{[23-44]}\end{array}$ & $\begin{array}{c}38 \\
{[30-54]}\end{array}$ & $\begin{array}{c}50 \\
{[35-67]}\end{array}$ & $<0.001$ \\
\hline Hypertension & $\begin{array}{c}19,914 \\
(92.0)\end{array}$ & $\begin{array}{c}17,170 \\
(92.4)\end{array}$ & $<0.001$ & $\begin{array}{l}7,377 \\
(83.6)\end{array}$ & $\begin{array}{l}8,906 \\
(86.9)\end{array}$ & $\begin{array}{l}7,264 \\
(87.2)\end{array}$ & $\begin{array}{l}7,002 \\
(87.1)\end{array}$ & $<0.001$ \\
\hline Diabetes & $\begin{array}{l}4,873 \\
(22.5)\end{array}$ & $\begin{array}{l}4,045 \\
(21.8)\end{array}$ & $<0.001$ & $\begin{array}{l}1,820 \\
(20.6)\end{array}$ & $\begin{array}{l}2,392 \\
(23.4)\end{array}$ & $\begin{array}{l}2,076 \\
(24.9)\end{array}$ & $\begin{array}{l}1,709 \\
(21.3)\end{array}$ & $<0.001$ \\
\hline Hyperlipidemia & $\begin{array}{l}4,455 \\
(20.6)\end{array}$ & $\begin{array}{l}4,014 \\
(21.6)\end{array}$ & $<0.001$ & $\begin{array}{l}2,631 \\
(29.8)\end{array}$ & $\begin{array}{l}3,346 \\
(32.7)\end{array}$ & $\begin{array}{l}3,220 \\
(38.7)\end{array}$ & $\begin{array}{l}2,492 \\
(31.0)\end{array}$ & $<0.001$ \\
\hline
\end{tabular}

Unless indicated otherwise, data are given as the mean $\pm \mathrm{SD}$, median [interquartile range], or $\mathrm{n}(\%)$. LOS, length of hospital stay; mRS, modified Rankin Scale.

\begin{tabular}{|lccc|}
\hline \multicolumn{4}{|c|}{ Table 2. Effect of Physician Volume on the Institutional Expertise of Specific Stroke Care and Infrastructure } \\
Quality Indicators \\
Institutional expertise and infrastructure & OR & P value & $95 \%$ Cl \\
Carotid endarterectomy & 1.44 & $<0.001$ & $1.21-1.71$ \\
Clipping of intracranial aneurysm & 5.02 & $<0.001$ & $2.25-11.22$ \\
Hematoma removal/draining & 5.00 & $<0.001$ & $2.24-11.17$ \\
Coiling of intracranial aneurysm & 1.39 & $<0.001$ & $1.25-1.54$ \\
Intra-arterial reperfusion therapy & 1.32 & $<0.001$ & $1.18-1.47$ \\
Stroke unit & 1.11 & $<0.001$ & $1.05-1.17$ \\
Operating room staffed 24/7 & 1.34 & $<0.001$ & $1.22-1.47$ \\
Interventional services coverage 24/7 & 1.36 & $<0.001$ & $1.24-1.49$ \\
Stroke registry & 1.03 & 0.075 & $1.00-1.07$ \\
\hline
\end{tabular}

$\mathrm{Cl}$, confidence interval; OR, odds ratio.

cians between 2010 and 2014 (Supplementary Table 3). The mean number of institutional physicians in hospitals did not differ significantly between 2010 and 2014. There was a decrease in the number of stroke physicians from 2010 to 2014 (mean decrease 0.6; $\mathrm{P}=0.020$ ), but the number of neurologists and neurosurgeons did not differ significantly in hospitals participating in both institutional surveys in 2010 and 2014. Stratified analyses of physician volume between the 2010 and 2014 surveys showed the same tendencies for the number of institutional physicians, neurosurgeons, and neurologists (data not shown).

The adjusted thresholds of the volume of board-certified neurosurgeons and stroke society board physicians for reductions in 30-day in-hospital mortality were 6 (OR 0.83 ; 95\% CI 0.75-0.92) and 6 (OR 0.84; 95\% CI 0.77-0.93), respectively, for ischemic stroke; 6 (OR 0.88 ; $95 \%$ CI 0.79 0.99 ) and 6 (OR $0.79 ; 95 \%$ CI $0.71-0.89)$, respectively, for $\mathrm{ICH}$; and 6 (OR 0.78 ; 95\% CI $0.68-0.90)$ and 6 (OR 0.77; $95 \%$ CI $0.68-0.87)$, respectively, for SAH. The number of board-certified neurologists was associated with 30-day in-hospital mortality in patients with ischemic stroke, with threshold of 4 to reduce 30-day in-hospital mortality (OR $0.89 ; 95 \%$ CI $0.80-0.98$ ). 


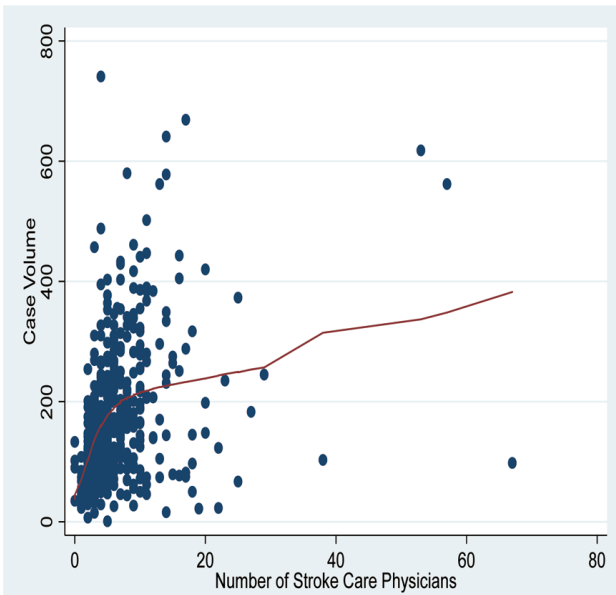

(A) Ischemic Stroke

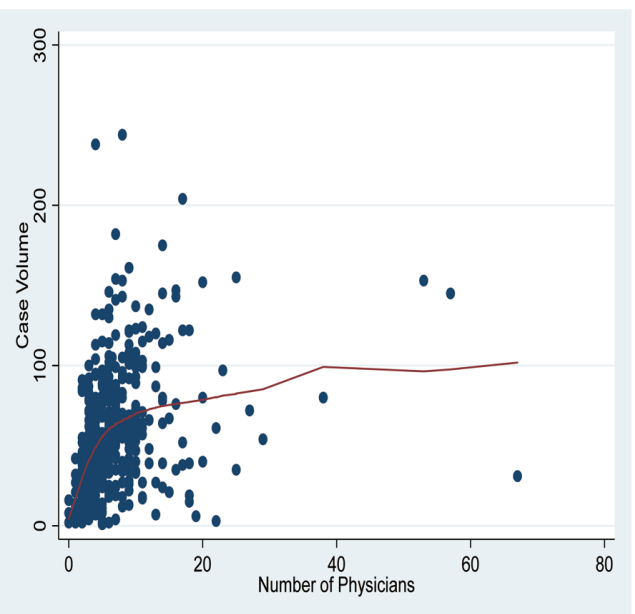

(B)Intracerebral Hemorrhage

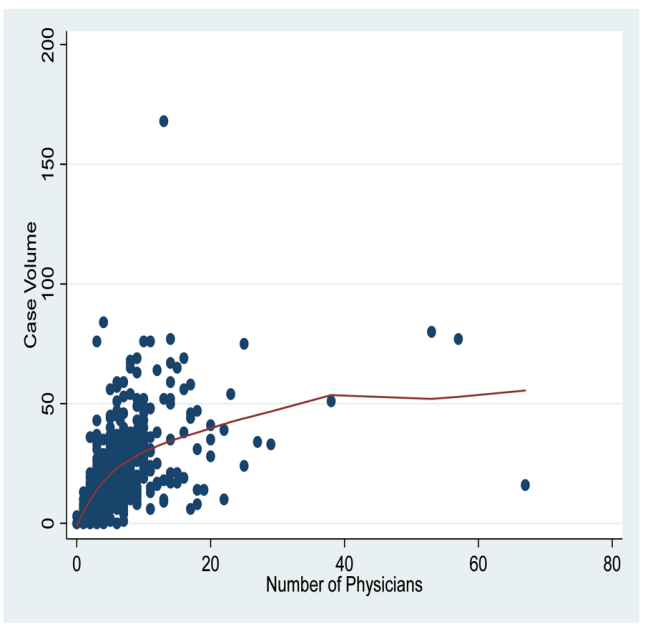

(C)Subarachnoid Hemorrhage

Figure 2. Associations between physician volumes per hospital, regardless of board certification status, and case volume for (A) ischemic stroke, (B) intracerebral hemorrhage, and (C) subarachnoid hemorrhage per hospital. Red line indicate the local meighted smoother estimate line.

\section{Discussion}

Using linkage data between 2 large nationwide databases, we found that a greater number of full-time stroke care physicians per hospital was associated with a lower risk of 30-day in-hospital mortality, regardless of the case volume of institutions and patient characteristics. The lower risk of in-hospital mortality was consistently observed for all stroke types. The correlation between case volume and the number of full-time stroke care physicians per hospital was weak. This suggests physician volume is an independent indicator of quality of care. Physician volume is also associated with some infrastructural quality indicators.

Regarding board certification status, we found that a greater number of board-certified neurosurgeons, stroke physicians, and endovascular surgeons was association with reduced 30-day in-hospital mortality of all types of stroke, but in different ways depending on the specialties and stroke types. Conversely, the number of board-certified neurologists was associated with reduced 30-day in-hospital mortality of ischemic but not hemorrhagic stroke.

Our findings are consistent with previous studies that reported that a higher physician volume is associated with lower 30-day ischemic stroke mortality. ${ }^{6}$ Importantly, our study identified that physician volume affects not only ischemic, but also hemorrhagic stroke, a more fatal type of stroke. The number of physicians is associated with better outcomes in other areas. Previous research has shown that higher physician volumes account for better outcomes in acute myocardial infarction ${ }^{14-16}$ and heart failure. ${ }^{17,18}$

Although the present study did not determine causality, there are a few plausible mechanisms underlying the cor- 
P for trend $=0.012$

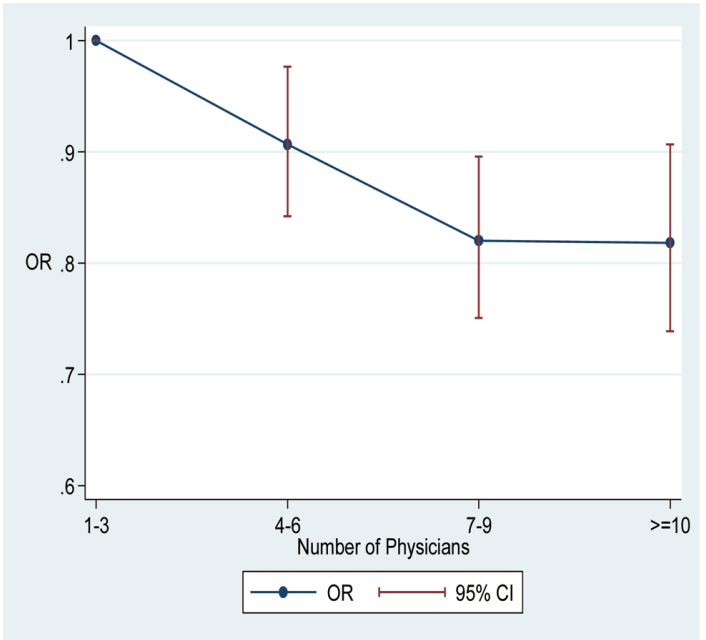

(A) Ischemic Stroke
P for trend $<0.001$

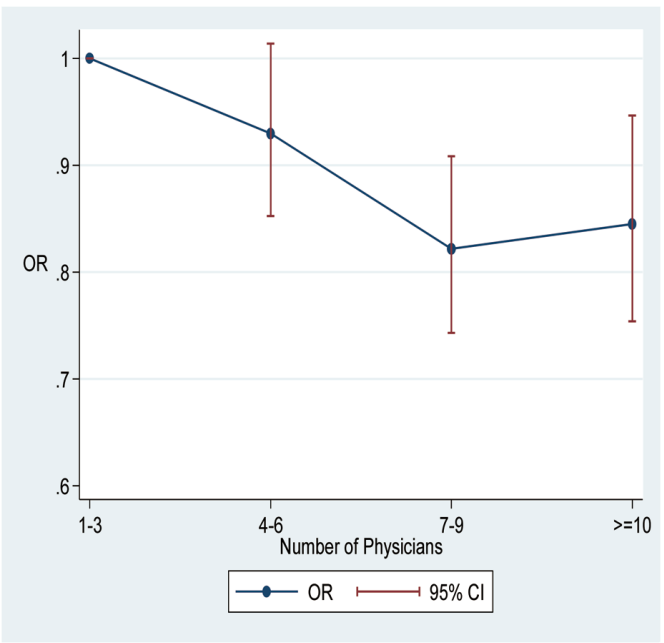

(B)Intracerebral Hemorrhage

$P$ for trend $=0.032$

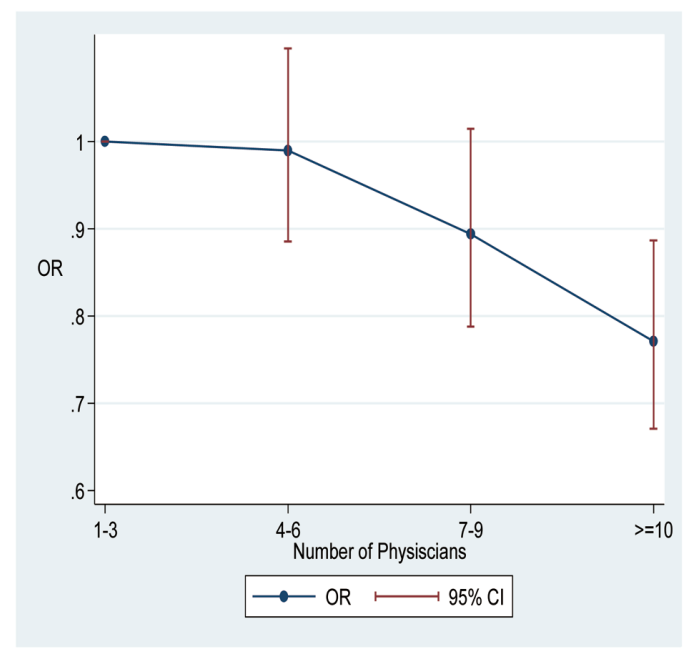

(c)Subarachnoid Hemorrhage

Figure 3. Associations between physician volumes, regardless of board certification status, and 30-day in-hospital mortality of patients with $(\mathbf{A})$ ischemic stroke, (B) intracerebral hemorrhage, and (C) subarachnoid hemorrhage after adjusting for sex, age, Charlson scores, presence of coma, comorbidity, hypertension, diabetes, hyperlipidemia, and stroke case volume per institute. $\mathrm{Cl}$, confidence interval; OR, odds ratio.

relations observed. Physician volume may be a good indicator of multidisciplinary stroke care team implementation, considering that comprehensive stroke care capabilities are associated with better outcomes. ${ }^{1}$ Implementation of stroke units with a multidisciplinary team is associated with lower mortality and disability after an acute stroke.4,19 There is growing consensus to regionalize the management of SAH and other types of stroke, because patients seem to have better outcomes with multidisciplinary care. ${ }^{\mathbf{2 0 , 2 1}}$

As noted in previous studies, hospitals with a higher volume of full-time stroke care physicians are more likely to provide specialized expertise, such as tissue plasminogen activator (t-PA) infusion and mechanical thrombectomy for patients with ischemic stroke, emergency hematoma removal for patients with $\mathrm{ICH}$, and clipping and coiling for patients with SAH in a timely manner. ${ }^{22}$ Furthermore, a higher number of full-time stroke physicians may prevent the interhospital transfer of patients due to staff availability, which may lead to poor outcomes in acute stroke patients. ${ }^{23}$

Volume thresholds may not simply represent higher availability of specific expertise provided by board-certified 


\begin{tabular}{|c|c|c|c|c|c|c|c|c|c|}
\hline \multirow{3}{*}{$\begin{array}{l}\text { No. physicians in } \\
\text { each institute }\end{array}$} & \multicolumn{9}{|c|}{ 30-day mortality } \\
\hline & \multicolumn{3}{|c|}{ Ischemic stroke } & \multicolumn{3}{|c|}{ Intracerebral hemorrhage } & \multicolumn{3}{|c|}{ Subarachnoid hemorrhage } \\
\hline & OR & $P$ value & $95 \% \mathrm{Cl}$ & OR & $P$ value & $95 \% \mathrm{Cl}$ & OR & $P$ value & $95 \% \mathrm{Cl}$ \\
\hline \multicolumn{10}{|c|}{ Board-certified neurosurgeons } \\
\hline 0-2 (Ref.) & 1.00 (Ref.) & & & 1.00 (Ref.) & & & 1.00 (Ref.) & & \\
\hline 3 & 0.99 & 0.832 & $0.91-1.08$ & 1.01 & 0.809 & $0.92-1.12$ & 0.97 & 0.665 & $0.85-1.11$ \\
\hline $4-5$ & 0.98 & 0.613 & $0.90-1.07$ & 1.00 & 0.926 & $0.91-1.11$ & 0.95 & 0.420 & $0.83-1.08$ \\
\hline$\geq 6$ & 0.83 & $<0.001$ & $0.75-0.92$ & 0.88 & 0.027 & $0.79-0.99$ & 0.78 & 0.001 & $0.68-0.90$ \\
\hline \multicolumn{10}{|c|}{ Board-certified neurologists } \\
\hline $0-1$ (Ref.) & 1.00 (Ref.) & & & 1.00 (Ref.) & & & 1.00 (Ref.) & & \\
\hline $2-3$ & 0.93 & 0.069 & $0.85-1.01$ & 1.00 & 0.931 & $0.90-1.10$ & 1.06 & 0.362 & $0.93-1.20$ \\
\hline$\geq 4$ & 0.89 & 0.020 & $0.80-0.98$ & 0.97 & 0.615 & $0.87-1.09$ & 0.92 & 0.272 & $0.80-1.06$ \\
\hline \multicolumn{10}{|c|}{ Board-certified stroke physicians } \\
\hline 0-3 (Ref.) & 1.00 (Ref.) & & & 1.00 (Ref.) & & & 1.00 (Ref.) & & - \\
\hline $4-5$ & 0.93 & 0.086 & $0.86-1.01$ & 0.99 & 0.747 & $0.90-1.08$ & 0.92 & 0.158 & $0.82-1.03$ \\
\hline$\geq 6$ & 0.84 & $<0.001$ & $0.77-0.93$ & 0.79 & $<0.001$ & $0.71-0.88$ & 0.77 & $<0.001$ & $0.68-0.87$ \\
\hline
\end{tabular}

The multilevel mixed-effects logistic regression model shows that the number of physicians in each institute is related to lower in-hospital mortality after adjusting for sex, age, Charlson scores, presence of coma, comorbidity, hypertension, diabetes, hyperlipidemia, and stroke case volume per institute. $\mathrm{Cl}$, confidence interval; OR, odds ratio.

physicians, but rather could be considered as indicators of the stroke care capabilities of the hospital. Our finding that the volume threshold of board-certified endovascular surgeons for ICH, for which no specific endovascular treatment is available, is almost the same as that for ischemic stroke and SAH may support this view. Admittedly, hospital volume may better reflect the joint effects required of multiple healthcare professionals, including physicians, nurses, and other clinical staff, to manage medical conditions. However, our finding is robust because hospital volume was adjusted for using hierarchical logistic regression models. Further studies are needed to elucidate the mechanisms underlying the impact of higher volumes of board-certified physicians on the reduced in-hospital mortality in stroke patients. In addition, changes in the number of physicians in each institute between 2010 and 2014 were relatively small, and stratified analyses suggested no remarkable effect of survey years on the present results.

This study is unique in that we observed heterogeneity of the volume thresholds in relevant specialties, based on stroke types, because no previous study reported a difference in the effect of specialty on stroke outcomes.

According to our 2010 institutional survey, board-certified neurosurgeons were mainly responsible for the care of ischemic stroke, $\mathrm{ICH}$, and $\mathrm{SAH}$ in $85.7 \%, 93.3 \%$, and $93.7 \%$ of participating institutions, respectively, whereas the corresponding figures for board-certified neurologists were $48.2 \%, 24.1 \%$, and $7.0 \%$. This may explain the association between an increased number of board-certified neurologists and better prognosis for ischemic but not hemorrhagic stroke in the present study.

Conversely, such thresholds of physician volume seem constant across all stroke types for board-certified neurosurgeons (6), stroke physicians (6), and endovascular surgeons (2 or 3). These figures are 1.5-, 2-, and 3-fold greater than the median number of these specialists, respectively, and beyond the IQR for the board-certified stroke physicians and endovascular surgeons. These facts indicate an across-the-board shortage of relevant specialists to further improve in-hospital mortality at an institutional level and an urgent need for centralization of stroke care in light of the recent surge in the aging population.

\section{Strengths and Limitations}

A strength of this study is that we used the nationwide claim database for the public health insurance system of Japan, which covers all stroke patients admitted to hospitals, regardless of patient age, unlike Medicare administrative claims in the US, resulting in greater generalizability of our results.

A few study limitations need to be recognized. First, there may be a selection bias of participating hospitals in this study. ${ }^{1}$ The present missing rate of patients was $20.4 \%$. Compared with patients included in the statistical analyses, patients excluded from the statistical analyses (i.e., patients from institutes that did not report details of physician volume and background characteristics of the patients) were slightly older and had a higher mortality, but better neurological prognosis (all $\mathrm{P}<0.001$ ). The number of cases of all stroke subtypes were also slightly higher in institutes not reporting details of physician volume and background patient characteristics than in institutes reporting this information (all $\mathrm{P}<0.001$; Supplementary Table 4). These differences may attenuate or potentiate the positive associations between physician volume and mortality. In addition, there may not be any systemic differences in the severity of patients' conditions between those institutes reporting detailed information and institutes not reporting this information. Therefore, we believed that the mechanism underlying the missing data in the present study was missing completely at random (MCAR) or missing at random (MAR). A previous study reported no important bias with missing rates varying from $5 \%$ to $60 \%$ under MCAR and MAR. ${ }^{24}$ Thus, we consider that there is no important bias from missing values in the present study. However, the results of the present study should be interpreted considering the possibility that the missing mechanism was neither MCAR nor MAR.

Second, because stroke diagnoses are based on claims and clinical information reported by physicians' hospitals, 
there may be some variability in the accuracy of the diagnosis. However, random sampling of the J-ASPECT Study participants revealed relatively reliable stroke diagnosis in the case of $\mathrm{SAH}^{11}$ and ischemic stroke (unpublished observation). Third, we focused on mortality and not on other important dimensions of quality, such as the processes of care. Fourth, we cannot rule out confounding of physician volume by other unmeasured patient and hospital characteristics. Fifth specialty-specific data are not likely generalizable to other countries with different practice patterns because neurosurgeons may not be as plentiful as in Japan. Sixth, the quality of emergency transport may also affect the mortality of stroke patients. Acute ischemic stroke patients with large vessel occlusion could benefit from direct transportation to an intervention center, but patients with non-large vessel occlusion need rapid intravenous thrombolysis in the nearest center. ${ }^{25}$ Our records lacked detailed information regarding emergency medical services (EMS). In addition, other confounding factors may have affected our analyses. Recently, we have started to connect these data to all records of Japanese EMS transportation results, which will clarify these points.

In addition, compared with the US, the availability of neurosurgeons for stroke centers is higher in Japan (92.7\% vs. $24-54 \%)^{\mathbf{8}, 26,27}$ and there are more endovascular surgeons in Japan ( $36 \%$ vs. $15-22 \%), \mathbf{8 , 2 6 , 2 7}$ but there is relative shortage of neurologists in Japan (47.8\% vs. 31-73\%); this will likely restrict the generalizability of our results to other countries. Finally, our data did not have detailed information of non-board-certified doctors and we therefore cannot determine whether the ratio of certified to non-certified stroke care physicians is a significant predictor of in-hospital mortality.

\section{Clinical Implications}

Our findings have clear implications. First, our findings provide evidence that an increase in the number of boardcertified physicians adds benefit to stroke care by reducing patient mortality, suggesting the need for current physicians to successfully maintain their competence and knowledge in their practice, and to develop new skills. Second, our findings regarding the number of specialists may be taken into consideration to improve the quality of stroke care at an institutional level. Third, for policy makers, the thresholds of physician volume may provide critical information for the centralization of stroke care through proper designation of comprehensive stroke centers, and to realize the potential shortage of stroke specialists that must be addressed to achieve better outcomes for stroke patients, at a national level.

\section{Conclusions}

Higher numbers of stroke care physicians were associated with reduced in-hospital mortality for all types of stroke. The volume threshold of board-certified physicians depends on the specialty and stroke type. This study provides critical information for the regionalization and centralization of stroke care and highlights the across-the-board shortage of relevant specialists that is limiting the ability of a superaging society to address the burden of stroke.

\section{Acknowledgments}

The authors thank the J-ASPECT Study Collaborators for their contributions. Part of the grant for the study was allocated to data collection. All Collaborators were involved in data collection. The authors thank Manabu Hasegawa and Yasuhiro Nishijima for discussions, and Arisa Ishitoko for secretarial assistance.

\section{Sources of Funding}

J-ASPECT Study (Principal Investigator: K.I.) was supported by Grants-in-Aid from the Japanese Ministry of Health, Labor and Welfare (H28-Shinkin-Ippan-001). This research was partially supported by the Japan Agency for Medical Research and Development (17ek0210088 h0001, 18ek0210088 h0002, JP18ek0210088) and KAKENHI grants $(25293314,18 \mathrm{H} 02914)$ from the Japan Society for the Promotion of Science.

\section{Disclosures}

T.K. is a member of Circulation Journal's Editorial Team. The remaining authors have no conflicts of interest to disclose.

\section{IRB Information}

This study was approved by the National Cerebral and Cardiovascular Center (ID R20058) and the Kyushu University Institutional Review Board, which waived the requirement for individual informed consent.

\section{Data Availability}

The data, methods, and materials used to conduct the research are documented in this report. Individual patient data are not publicly available because of the memoranda signed by directors of the participating hospitals and the Principal Investigator of the J-ASPECT Study Group.

\section{References}

1. Iihara K, Nishimura K, Kada A, Nakagawara J, Ogasawara K, Ono J, et al. Effects of comprehensive stroke care capabilities on in-hospital mortality of patients with ischemic and hemorrhagic stroke: J-ASPECT study. PLoS One 2014; 9: e96819.

2. Joynt KE, Orav EJ, Jha AK. The association between hospital volume and processes, outcomes, and costs of care for congestive heart failure. Ann Intern Med 2011; 154: 94-102.

3. Ross JS, Normand SL, Wang Y, Ko DT, Chen J, Drye EE, et al. Hospital volume and 30-day mortality for three common medical conditions. N Engl J Med 2010; 362: 1110-1118.

4. Svendsen ML, Ehlers LH, Ingeman A, Johnsen SP. Higher stroke unit volume associated with improved quality of early stroke care and reduced length of stay. Stroke 2012; 43: 3041 - 3045 .

5. Hall RE, Fang J, Hodwitz K, Saposnik G, Bayley MT. Does the volume of ischemic stroke admissions relate to clinical outcomes in the Ontario stroke system? Circ Cardiovasc Qual Outcomes 2015; 8(Suppl 3): S141 -S147.

6. Tung YC, Chang GM, Chen YH. Associations of physician volume and weekend admissions with ischemic stroke outcome in Taiwan: A nationwide population-based study. Med Care 2009; 47: 1018-1025.

7. Kurogi R, Nishimura K, Nakai M, Kada A, Kamitani S, Nakagawara J, et al. Comparing intracerebral hemorrhages associated with direct oral anticoagulants or warfarin. Neurology 2018; 90: e1143-e1149.

8. Iihara K, Nishimura K, Kada A, Nakagawara J, Toyoda K, Ogasawara K, et al. The impact of comprehensive stroke care capacity on the hospital volume of stroke interventions: A nationwide study in Japan: J-ASPECT study. J Stroke Cerebrovasc Dis 2014; 23: 1001-1018.

9. Onozuka D, Hagihara A, Nishimura K, Kada A, Nakagawara J, Ogasawara K, et al. Prehospital antiplatelet use and functional status on admission of patients with non-haemorrhagic moyamoya disease: A nationwide retrospective cohort study (J-ASPECT study). BMJ Open 2016; 6: e009942.

10. Nishimura $K$, Nakamura F, Takegami M, Fukuhara S, Nakagawara J, Ogasawara K, et al. Cross-sectional survey of workload and burnout among Japanese physicians working in stroke care: The nationwide survey of acute stroke care capacity for proper designation of comprehensive stroke center in Japan (J-ASPECT) study. Circ Cardiovasc Qual Outcomes 2014; 7: 414-422.

11. Kurogi R, Kada A, Nishimura K, Kamitani S, Nishimura A, Sayama T, et al. Effect of treatment modality on in-hospital outcome in patients with subarachnoid hemorrhage: A nation- 
wide study in Japan (J-ASPECT Study). J Neurosurg 2018; 128: $1318-1326$.

12. Royston P, Sauerbrei W. Stability of multivariable fractional polynomial models with selection of variables and transformations: A bootstrap investigation. Stat Med 2003; 22: 639-659.

13. Oda T, Minatoya K, Sasaki H, Tanaka H, Seike Y, Itonaga T, et al. Surgical indication for chronic aortic dissection in descending thoracic and thoracoabdominal aorta. Circ Cardiovasc Interv 2017; 10: e004292.

14. Chen J, Rathore SS, Wang Y, Radford MJ, Krumholz HM. Physician board certification and the care and outcomes of elderly patients with acute myocardial infarction. J Gen Intern Med 2006; 21: 238-244.

15. Park S, Sasaki N, Morishima T, Ikai H, Imanaka Y. The number of cardiologists, case volume, and in-hospital mortality in acute myocardial infarction patients. Int J Cardiol 2013; 168: 44704471.

16. Casale PN, Jones JL, Wolf FE, Pei Y, Eby LM. Patients treated by cardiologists have a lower in-hospital mortality for acute myocardial infarction. J Am Coll Cardiol 1998; 32: 885-889.

17. Kulkarni VT, Ross JS, Wang Y, Nallamothu BK, Spertus JA, Normand SL, et al. Regional density of cardiologists and rates of mortality for acute myocardial infarction and heart failure. Circ Cardiovasc Qual Outcomes 2013; 6: 352-359.

18. Jong P, Gong Y, Liu PP, Austin PC, Lee DS, Tu JV. Care and outcomes of patients newly hospitalized for heart failure in the community treated by cardiologists compared with other specialists. Circulation 2003; 108: $184-191$

19. Stroke Unit Trialists' Collaboration. Organised inpatient (stroke unit) care for stroke. Cochrane Database Syst Rev 2013; 9: CD000197.

20. Jaja BNR, Saposnik G, Lingsma HF, Macdonald E, Thorpe KE, Mamdani M, et al. Development and validation of outcome prediction models for aneurysmal subarachnoid haemorrhage: The SAHIT multinational cohort study. BMJ 2018; 360: j5745.

21. Imamura H, Sakai N, Sakai C, Fujinaka T, Ishii A. Endovascular treatment of aneurysmal subarachnoid hemorrhage in Japanese Registry of Neuroendovascular Therapy (JR-NET) 1 and 2. Neurol Med Chir (Tokyo) 2014; 54: 81-90.

22. Kada A, Nishimura K, Nakagawara J, Ogasawara K, Ono J, Shiokawa Y, et al. Development and validation of a score for evaluating comprehensive stroke care capabilities: J-ASPECT Study. BMC Neurol 2017; 17: 46.

23. Froehler MT, Saver JL, Zaidat OO, Jahan R, Aziz-Sultan MA, Klucznik RP, et al. Interhospital transfer before thrombectomy is associated with delayed treatment and worse outcome in the STRATIS Registry (Systematic Evaluation of Patients Treated With Neurothrombectomy Devices for Acute Ischemic Stroke). Circulation 2017; 136: 2311-2321.

24. Kristman V, Manno M, Côté P. Loss to follow-up in cohort studies: How much is too much? Eur J Epidemiol 2004; 19: 751 - 760.

25. Gerschenfeld G, Muresan IP, Blanc R, Obadia M, Abrivard M, Piotin M, et al. Two paradigms for endovascular thrombectomy after intravenous thrombolysis for acute ischemic stroke. JAMA Neurol 2017; 74: 549-556.

26. Ruland S, Gorelick PB, Schneck M, Kim D, Moore CG, Leurgans S. Acute stroke care in Illinois: A statewide assessment of diagnostic and treatment capabilities. Stroke 2002; 33: 1334-1339.

27. Goldstein LB. Statewide hospital-based stroke services in North Carolina: Changes over 10 years. Stroke 2010; 41: 778-783.

\section{Supplementary Files}

Please find supplementary file(s);

http://dx.doi.org/10.1253/circj.CJ-20-1214 